\title{
Organic chemistry in the new millennium
}

\author{
Abbreviated version of opening lecture at the Ibn Sina Symposium on Heterocyclic \\ Chemistry atAlexandria, Egypt in March 2000 \\ by Alan R. Katritzky, University of Florida
}

(received 27 Mar 00; accepted 21 Sep 00; published on the web 29 Sep 00)

\section{The best of times - a brilliant future!}

The Opening of the new Millennium finds Organic Chemistry in the midst of immense changes. Enormous opportunities have opened up. Fantastic new instrumentation includes powerful gas chromatography-mass spectroscopy links and rapidly developing and even more powerful liquid chromatography mass spectroscopy options. NMR advances at a seemingly ever-increasing pace and offers us the possibility of rapid measurements on very small quantities. The X-ray analysis of powders is already becoming a routine.

Additional new and powerful technologies include the whole range of combinatorial chemistry and parallel synthesis techniques. Increasing automatization has allowed an explosion in the number of novel compounds synthesized. High throughput screening enables the rapid assessment of the biological potential of all these new derivatives.

All this is backed up by veritable information explosion. With computers of ever increasing capacity available for all, we can now go online to access powerful databases such as those provided by Chemical Abstracts Service, by Beilstein (the Crossfire search system) and by MDL such as REACS.

\section{For some - a frightening prospect!}

Despite of all these wonderful opportunities, and indeed to a certain extent because of them, many chemists in less well endowed universities face a frightening prospect for the future. The cost of doing research is ever increasing: increasing for chemicals, for equipment, for spectrometers and for information. The more possibilities there are, the more expensive it becomes and the more difficult it is to "keep up with the Joneses".

There is ever increasing competition for available resources. Granting agencies, both international and national, are drawing more and more applicants whose numbers increase at a far greater rate than do available resources. Individual universities and individual departments as well as most research groups are subject to more and more financial pressure.

Library facilities are decreasing in relative terms as regards the number of journals, books and databases contained in any single library to the total that is available. The escalating cost of journals has put even well endowed university libraries in developed countries in great financial difficulties.

At the same time in many countries individual chemists are encountering problems in publishing their work. The top journals are all chasing "novel \& significant” results. Many 
second-tier journals have disappeared by amalgamation. A real question arises: should only the most significant work be published?

In summary the difficulties are such that there is a danger of increasingly polarizing the world community of organic chemists into a small group of haves and a much larger number of have-nots.

Figure 1. Statistics for $17^{\text {th }}$ International Conference of Heterocyclic Chemistry (Vienna, Austria, Aug 99).

12 Plenary \& Award Lectures 36 Invited Lectures 72 Oral Presentations 594 Posters 1156 Scientists Registered +250 accompanying persons

\begin{tabular}{llllllll} 
ASIA & \multicolumn{3}{l}{ EUROPE } & \multicolumn{2}{l}{ SWITZERLAND22 } & AFRICA & \\
JAPAN & 164 & Germany & 115 & SPAIN & 19 & EGYPT & 18 \\
TAIWAN & 20 & UNITED & 96 & SLOVENIA & 18 & SOUTH AFRICA & 3 \\
& & KINGDOM & & & & & \\
TURKEY & 20 & AUSTRIA & 54 & LATVIA & 12 & AUSTRALASIA & \\
ISRAEL & 11 & HUNGARY & 52 & NORWAY & 7 & AUSTRALIA & 11 \\
CHINA & 8 & RUSSIA & 51 & ROMANIA & 7 & NEW ZEALAND & 2 \\
KOREA & 6 & FRANCE & 48 & UKRAINE & 7 & LATIN & \\
& & & & & & AMERICA & \\
THAILAND & 4 & DENMARK & 30 & CROATIA & 6 & ARGENTINA & 9 \\
INDIA & 3 & BELGIUM & 27 & FINLAND & 6 & MEXICO & 3 \\
SAUDI & 2 & ITALY & 26 & IRELAND & 5 & CHILE & 2 \\
ARABIA & & & & & & & \\
KUWAIT & 1 & SWEDEN & 25 & GREECE & 3 & BRAZIL & 1 \\
& & SLOVAKIA & 24 & BULGARIA & 2 & NORTH & \\
& & & & & & AMERICA & \\
& & CZECH & 23 & LITHUANIA & 2 & USA & 102 \\
& & REPUBLIC & & & & & \\
& & POLAND & 23 & BELARUS & 1 & CANADA & 11
\end{tabular}

\section{An optimistic message for all organic chemists}

Compared with many other subjects we are most fortunate to work in organic chemistry. Chemical structure provides a universal basis - a basis, which remains constant in time, place and context. Chemical structure is unaffected by historical, political or cultural influences. We are in no danger of exhausting opportunities for innovation in Organic Chemistry. There is a limitless range of structures possible; the number with molecular weight $£ 500$ far exceeds the number of particles in the universe.The advance of medicine is extremely fast and our 
understanding of diseases increases constantly; the understanding, which is expressed more and more in molecular terms.

The availability of high throughput screening to discover leads, and of organic synthesis to exploit them, will continue to increase. At present some $15 \%$ of gross national product of the USA is used for medical care, and this percentage can be expected to double within the foreseeable future.

\section{The opportunities}

All this means that in terms of chemical structures there are as good fish in the sea as ever came out of it. Moreover, sound and interesting research continues to be done in all continents. This is well illustrated by Fig. 1, which gives some statistics for the 17th International Conference of Heterocyclic Chemistry, held in Vienna, Austria in August 1999.

Computational chemistry is there for anybody to explore. Modern powerful QSAR (quantitative structure-activity relationships) and QSPR (property) techniques not only correlate, but also provide both predictions and insights into many physical, chemical, biological and technological properties.

In this lecture I want to demonstrate that publication is now available for all sound work without cost to author or reader, and that compounds can be sold for testing and the proceeds used for research support. Furthermore, I believe that the decrease in the amount of fundamental research carried out in industry provides much increased opportunities for academic scientists to work closely with and be supported by industry.

Figure 2. Publication Possibilities for Organic Chemistry Original Research.

Disappearance of Many Second Tier Journals

Amalgamation of:

$\begin{array}{ll}\begin{array}{l}\text { Bull Soc Chim de France } \\ \text { Bull Soc Chim de France } \\ \text { Bull Soc Chim Belges } \\ \text { Liebigs Annalen der Chemie } \\ \text { (Germany) }\end{array} & \begin{array}{l}\text { European Journal of } \\ \text { Organic Chemistry } \\ \$ 2698 \text { / annum }\end{array} \\ \begin{array}{l}\text { Chemische Berichte (Germany) } \\ \text { Recueil de Chimie (Poland) } \\ \text { Gazzetta Chimica Italiana (Italy) } \\ \text { Chimica Chronika (Greece) }\end{array} & \begin{array}{l}\text { European Journal of } \\ \text { Inorganic Chemistry } \\ \text { Revista Chimica (Portugal) }\end{array} \\ \text { Annales de Quimica (Spain) } & \end{array}$

also Acta Chemica Scandinavica merged into J Chem Soc (UK) 
A large number of Organic Chemistry Journal still remain

Some are well-known e.g. JHC, JOC, H, OL, PERKIN I and II, S, SL, T, TL

But many are hardly known and have small circulations

New Free Journal ARKIVOC (Archive for Organic Chemistry)

Although openings for the publication original research of organic chemistry have decreased recently by the disappearance and amalgamation of many second-tier journals (see Fig. 2), the new journal ARKIVOC offers a valuable alternative.

ARKIVOC is designed for Universal on-demand distribution at no cost to authors or subscribers. It is accessible on the WWW electronically - free to all. The Web edition is specifically formatted in pages to facilitate downloading and binding into hard copy - for free. A hard copy edition will also be available to send to deposit libraries and for purchase by anybody on subscription. However there is no need for anybody to pay because they can just download and bind their own copies if they so wish. It is planned to keep ARKIVOC in perpetuity eventually on several servers worldwide for rapid access.

Submitting, refereeing and editing of manuscripts for ARKIVOC

Instructions for authors are available at http://www.arkat-usa.org/

Authors should contact the ARKIVOC Coordinating Editor by e-mail, enclosing the complete MS (including the names of the authors, and a graphical abstract) and names of up to 6 suggested Referees taken (no more than 2 from any one continent from a list (presently around 300) available on the web. The Coordinating Editor designates a MS reference number, a Scientific Editor, and Referees, normally selected from the list given.

The Coordinating Editor e-mails the manuscript to the designated Referees. The Referees report to the designated Scientific Editor with instructions for revision of the manuscript if necessary. When the author and Scientific Editor have come to agreement, the Scientific Editor will send the accepted MS to the Technical Editor.

The journal ARKIVOC is managed by a Control Board. The present composition of the Control Board is given in Figure4.

ARKAT: Archive for Analysis and Testing

ARKAT is a new not-for-profit foundation based in Switzerland, initially financed by a personal gift but which aims to become self-supporting. The main objectives of ARKAT are to promote education and research, particularly in organic chemistry.

ARKAT will publish the new electronic and print journal ARKIVOC. To cover the costs of the free distribution of ARKIVOC, and to provide financial assistance for research in organic chemistry world wide, a major projected source of income is from the ARKAT Compound Depository Scheme.

ARKAT Compound Depository

Based in Switzerland, the ARKAT Depository will accept the donation of properly characterized compounds from all. In particular it is hoped that authors who publish papers in ARKIVOC will send some of their compounds to the Depository. 
The structures of all compounds in the depository will be published on the web and it will be the aim of ARKAT to sell these compounds to all who are interested in using them for biological and other testing.

Of the gross sale proceeds, $50 \%$ will immediately be made available to the donors, and the other $50 \%$ will be used first to manage ARKAT and ARKIVOC and then all the remainder returned to support science.

Figure 4. ARKIVOC - Control Board Composition.

Chairman:

C.W. Rees (Imperial Coll, London, UK)

Scientific Editor + Secretary:

C. A. Ramsden (Univ Keele, UK)

Scientific Editors:

M. Begtrup (Roy Pharm. Sch. Copenhagen, Denmark)

T. Gilchrist (Univ Liverpool, UK)

A. P. Krapcho (Univ Vermont, USA)

A. D. Marchand (Univ North Texas, USA)

J.G. Schantl (Univ Innsbruck, Austria)

G. S. Subba Rao (Indian Institute of Science, Bangalore)

Scientific Editor: (Accounts and Reviews)

E. Scriven (Reilly Industries, Indianapolis, USA)

Coordinating Editors:
A. J. Boulton (Univ East Anglia, UK)
R. A. Jones (Univ East Anglia, UK)
Chair Editorial Board of Refs:
G. Newkome (Univ S. Florida, USA)
Chair Anniversary Issues:
A. R. Katritzky( University of Florida, USA)
Chair Thematic Issues:
(to be appointed)
Additional Members:
P. Thind (ARKAT, Zurich Switzerland)

Mode of Operation of ARKAT Compound Depository

The compound donor transfers a list of compounds electronically to the ARKAT Compound Manager together with either (a) corresponding ARKIVOC MS or (b) data sheets (for formatting the list of data sheets get instructions from WWW).

ARKAT manager replies electronically accepting (or rejecting) each compound based mainly on quality of characterization. 
Compound donor sends compounds to Zurich together with pricing protocol (for packaging and setting prices, get instructions from WWW).

Quality control screening by inspection: up to $10 \%$ of specimens selected and sent for NMR examination.

ARKAT manager accepts compounds based on results of NMR and places on web (compound database is available to all).

Company or other purchaser selects quantities and nature of compounds and orders electronically (see instructions on WWW).

ARKAT weight out compounds and sends out by Courier to purchaser together with invoice. Company pays (see instructions on WWW).

ARKAT places $50 \%$ of proceeds for each compound in dedicated account of each compounds donor (see WWW on access).

Compound donor requests electronically payment up to account balance (see WWW for information).

\section{Working closely with industry}

Enormous opportunities now exist for organic chemists to work closely with industry. Up until approximately 1985, most large companies had basic research units; however, increasing financial pressure on companies has led to the present situation where much less fundamental research is now carried out in industry. The result is that companies now rely almost exclusively on universities for new leads and ideas.

The advantages to industry of supporting research in a university are quite substantial. No capital costs are incurred for new buildings or equipment. There is no increase in the company head count, and no long-term commitment - frequently support is provided one year at a time. The company gains access to novel approaches, and access to other research at the institution where it is supporting a project, together with obvious recruiting advantages.

The advantages to universities of working with industry are numerous and obvious! There are a number of perceived disadvantages, but these are mostly non-existent. Much of the research can be published; although there is often a delay. It is our experience that students like to do useful research. In particular a mix of research done with industry and research done without any industrial commitment can be very attractive.

\section{How to attract industrial support}

There is no easy answer to this and many different avenues have to be attempted. Some advantageous bridges may be formed through ex-students now working in industry, by casual contacts at conferences, and in particular, at conference posters sessions. Another useful point is keeping watch on publications from industry and approaching the authors.

However, it is very important also to have the right attitude. Remember that most industrial chemists are hardworking, competent and expert in their own areas. There is no substitute for knowledge; it is important for academic researchers who wish to gain industrial support to have read widely, and to know the background to the potential projects. Nothing can replace a lot of hard work. It is important to avoid overconfidence and to remember that industry does not 
believe in tenure. Above all, gentle persistence is required, success does not come easily and it is necessary to try and try again: "if you do not ask you will not receive."

\section{How to retain industrial support}

Having obtained industrial support it is important to try to retain it. Meticulous record keeping is essential Provide regular and accurate written reports, promptly. Document new compounds with analyses and spectra. Realize above all that records are probably less important to your immediate contact in industry than to his/her boss.

You need work to build confidence, and to realize that such confidence is built only slowly. Be realistic and reliable, set deadlines that can be kept. Criticize sparingly the way in which you perceive the industry works and have empathy to needs and above all to changing needs.

Remember that industrial companies need to turn a profit and that economics is the basis for industry. Companies are subject to the market place and sudden changes can occur. Their stability is often frail!

\section{Action points}

Go to ARKAT Web Page at http://www.arkat-usa.org/

Register as a member of ARKAT (no cost or obligation).

Submit a paper to ARIVOC - contact Dr. A. J. Boulton as a Coordinating Editor.

Submit compounds to ARKAT depository (see instructions on the web). 